\title{
Determination of ovarian cycle in Goeldi's monkey (Callimico goeldii) via the measurement of steroids and peptides in plasma and urine
}

\author{
C. R. Pryce ${ }^{1}$, M. Jurke ${ }^{1}$, H. J. Shaw ${ }^{2}$, I. G. Sandmeier $^{1}$ and \\ M. Doebeli ${ }^{3}$ \\ ${ }^{1}$ Anthropologisches Institut, Universität Zürich-Irchel, Winterthurerstrasse 190, 8057 Zürich, \\ Switzerland; 'Institute of Zoology, Zoological Society of London, Regent's Park, London NW1 4RY, \\ $U K$; and ${ }^{3}$ Klinik für Andrologie und Gynäkologie, Veterinärmedizinische Fakultät, \\ Winterthurerstrasse 260, 8057 Zürich, Switzerland
}

\begin{abstract}
Goeldi's monkey (Callimico goeldii) is an endangered species of New World primate. The present study provides the first description of the non-conception ovarian cycle in this species based on circulating reproductive steroid and peptide hormones. The data obtained were used to validate a non-invasive system for monitoring cyclicity based on urinary reproductive steroid metabolites. Nine sexually mature females were studied. In three females, matched blood and urine samples were collected once every 2-3 days for 90-120 days; in three other females, matched blood and urine samples were collected daily for 14-20 days for one peri-ovulatory period; and in the remaining three females, urine samples only were collected once every $1-3$ days for 40-60 days. Plasma progesterone, oestrone-3-conjugates and bioactive $\mathrm{LH}$ were measured, in addition to urinary pregnanediol-3 $\alpha$-glucuronide and oestrone-3-conjugates. The mean maximum concentration of plasma LH occurred 1-2 days before a significant rise in plasma progesterone, which was considered to occur 1 day after ovulation. On the basis of plasma progesterone titres, the duration of the ovarian cycle was estimated as $23.9 \pm 0.4$ days $(n=9)$, and constituted a follicular phase of $10.7 \pm 0.3$ days and a luteal phase of $13.5 \pm 0.3$ days. Urinary pregnanediol-3 $\alpha$-glucuronide demonstrated a high correlation with plasma progesterone $(r=0.8)$, and demonstrated a significant rise at the same time as plasma progesterone. Application of this urinary progesterone metabolite to determine whether a female was in a follicular phase (pregnanediol-3 $\alpha$-glucuronide $<0.20 \mu \mathrm{g} \mathrm{mg}^{-1}$ creatinine) or a luteal phase (pregnanediol-3 $\alpha$-glucuronide $>0.20 \mu \mathrm{g} \mathrm{mg}^{-1}$ creatinine) provided an accurate and reliable non-invasive system for monitoring reproductive state and timing ovulation in this endangered primate. Urinary oestrone-3conjugates were less accurate and reliable than pregnanediol-3 $\alpha$-glucuronide: while plasma and urinary oestrone-3-conjugates were generally higher during the luteal phase than during the follicular phase, a marked increase in their concentration did not occur until 3-5 days after inferred ovulation.
\end{abstract}

\section{Introduction}

Goeldi's monkey (Callimico goeldii) is a small $(450-650 \mathrm{~g})$, clawed South American primate, indigenous to the upper Amazon Basin from south-eastern Peru and northern Bolivia to southern Colombia (Wolfheim, 1983). Goeldi's monkey is rare and, indeed, is officially recognized as an endangered species. Captive populations of Goeldi's monkey have been established and are coordinated and managed at an international level (Warneke, 1992). Studies of this species in captivity have been concerned with reproductive behaviour (Beck et al., 1982; Carroll, 1982, 1985) and various aspects of reproductive endocrinology. The data available on female reproductive

Received 18 November 1992. endocrinology of Goeldi's monkey constitute descriptions of the ovarian cycle and of pregnancy based on the metabolites of reproductive steroid and peptide hormones in urine or faeces (Carroll et al., 1989, 1990; Christen et al., 1989; Ziegler et al., 1989, 1990a; Pryce and Döbeli, 1992; Jurke et al., in press). Ziegler et al. (1989, 1990a) compared the urinary excretion profile of oestrone-3-conjugates with that for urinary bioactive $\mathrm{LH}$ and found that the concentration of the former started a marked and sustained increase on the same day as the urinary LH peak occurred, strongly suggesting that conjugated oestrogen excretion is high in the luteal phase relative to the follicular phase of the ovarian cycle. Carroll et al. (1990) demonstrated concurrent cyclical changes in urinary oestrone-3-conjugates, progesterone and pregnanediol-3 $\alpha$-glucuronide, further suggesting that conjugated oestrogen excretion is high in the luteal phase of the ovarian cycle. The authors concluded that all three urinary Downloaded from Bioscientifica.com at 04/26/2023 12:39:07PM
and Fertility Ltd
via free access 
(conjugated) steroids represent reliable indicators of ovarian function.

Against this background, we considered it important to provide the first description of the ovarian cycle in Goeldi's monkey based on concentrations of reproductive steroid and peptide hormones in blood, and to use these data in an attempt to establish and validate an indirect description of the ovarian cycle based on the urinary excretory products of these reproductive hormones.

\section{Materials and Methods}

\section{Animals}

Nine captive-born female Goeldi's monkeys were the subjects of this study which comprised three separate experiments each involving three females. At the onset of the study in 1991, the animals were aged 1.6-9.0 years and their body weights were 440-620 g. Females in Expt 2 were kept in outdoor enclosures measuring $16 \mathrm{~m}^{3}$; temperature and humidity fluctuated between 18 and $30^{\circ} \mathrm{C}$ and 30 and $80 \%$, respectively. Females in Expts 1 and 3 were maintained in indoor cages measuring $6 \mathrm{~m}^{3}$; they were exposed to attenuated natural light and a $12 \mathrm{~h}$ light: $12 \mathrm{~h}$ dark cycle of artificial illumination, with room temperature and relative humidity maintained at $25-28^{\circ} \mathrm{C}$ and $55-65 \%$, respectively. All animals were fed daily at 08:00 h with a high protein porridge containing vitamin and mineral supplements, and at 13:30 h with fruits and vegetables. Mouse pups, mealworms or crickets were also fed daily and high-protein monkey pellets (Nafag, Animal Nutrients \& Feeds, Gossau) and drinking water (containing iron syrup during periods of blood sampling) were available to the animals ad libitum.

\section{Collection of blood and urine samples}

Experiment 1. Samples were collected from three females living under different social conditions: one female was housed together with an unrelated adult female, another with two unrelated adolescent males, and the third with an unrelated adult male. The first two females were nulliparous and had never been in tactile contact with an unrelated adult male. The third female was multiparous and during the period of sample collection was separated from its mate for an estimated 4 days before and 4 days after the estimated day of ovulation (estimate based on the profile obtained for urinary pregnanediol-3 $\alpha$-glucuronide, see below). Pregnancy was thereby avoided throughout the study period. A urine sample followed within $15 \mathrm{~min}$ by a blood sample were collected on each Monday, Wednesday and Friday between 07:45 and 08:00 h, for 119, 120, and 89 consecutive days from each female, respectively. In the case of urine collection, the collector would enter the home cage at the onset of the light phase and clean-catch the first void of urine in a plastic container (Jurke et al., in press); $0.5-1.0 \mathrm{ml}$ of urine was transferred into a cryotube and stored at $-25^{\circ} \mathrm{C}$ before analysis. The female was then caught and transferred to a restraint apparatus (Hearn, 1977) for collection of blood samples. Without sedation, but only after a training period during which animals had been exposed to restraint on ten occasions, blood samples of $0.3 \mathrm{ml}$ were collected via puncture of the femoral vein into a heparinized $1 \mathrm{ml}$ syringe (Primo, Single Use: Merck ABS, Dietikon, Switzerland) fitted with a 27-gauge needle (Microlance: Merck ABS, Dietikon). Blood samples were placed directly on ice and centrifuged at $1500 \mathrm{~g}$ for $20 \mathrm{~min}$ so that the plasma could be removed and stored at $-25^{\circ} \mathrm{C}$ before analysis. All plasma samples were analysed for their content of immunoactive progesterone and oestrone-3-conjugates; where sufficient plasma was available, samples were also analysed for bioactive LH. All urine samples were analysed for their content of immunoactive pregnanediol-3a-glucuronide and oestrone-3conjugates and creatinine.

Experiment 2. The second study was carried out with three sexually mature females, two multiparous and one nulliparous, each permanently housed with an intact adult male. A pilot study was carried out using the synthetic prostaglandin $F_{2 \alpha^{\prime}}$ cloprostenol (Estrumate: Coopers, Swiss Serum and Vaccine Institute, Berne) to establish a method for controlling female reproductive condition in such adult pairs of Goeldi's monkey. Cloprostenol acts as a luteolysin from mid-luteal phase onwards in the closely related common marmoset, Callithrix jacchus, when injected i.m. at a dose of $1.25 \mu \mathrm{g} \mathrm{kg}^{-1}$ (Summers et al., 1985), and can be routinely used, as it is in our laboratory, to regulate reproductive condition. Five sexually mature females, each housed with a sexually mature male, were studied during one conception cycle to examine the existence of a luteolytic effect of cloprostenol in Goeldi's monkey. Cloprostenol was administered i.m. at doses of $1.25-20.0 \mu \mathrm{g} \mathrm{kg}^{-1}$ between days 17 and 40 after inferred ovulation (i.e. inferred from a consistent increase in the concentration of urinary pregnanediol-3 $\alpha$ glucuronide - see below). If an injection of the lowest dose on days 17-20 after ovulation did not induce luteolysis (estimated by a marked decrease in the concentration of urinary pregnanediol-3 $\alpha$-glucuronide within four days of treatment), the female was given a second injection of cloprostenol that was twice the amount $\left(2.5 \mu \mathrm{g} \mathrm{kg}^{-1}\right)$ that had been given in the first injection five days previously. This procedure was continued in each female until luteolysis was estimated to have occurred.

In this experiment, commencing on the fifth day after cloprostenol-induced luteolysis, a blood sample and a matching urine sample were collected from each female between 08:00 and $09: 00 \mathrm{~h}$ on 14-20 consecutive days. Blood samples (0.2$0.3 \mathrm{ml}$ ) were collected using the method described above. Females were then transferred to a small metabolism cage for $30-60 \mathrm{~min}$; urine $(0.2-1.0 \mathrm{ml})$ was aspirated from a plastic collecting tray and stored at $-25^{\circ} \mathrm{C}$ before analysis. Plasma samples were analysed for their content of immunoactive progesterone; urine samples were analysed for their content of immunoactive pregnanediol-3 $\alpha$-glucuronide and oestrone-3conjugates and creatinine.

Experiment 3. In each of two females housed temporarily with adolescent males, and one post-partum female housed with its mate and offspring, urine samples only were collected 3-4 times per week, with a maximum intersampling interval of three days (Friday to Monday), for 40-60 days. Samples were analysed for their content of immunoactive pregnanediol-3 $\alpha$ glucuronide and oestrone-3-conjugates and creatinine. Expt 3 was Downloaded from Bioscientifica.com at 04/26/2023 12:39:07PM 
Table 1. Extraction efficiency, assay sensitivity, precision and accuracy for the hormones measured

\begin{tabular}{|c|c|c|c|c|c|}
\hline Hormone & $\begin{array}{c}\text { Extraction } \\
\text { efficiency } \\
(\%)^{\mathrm{a}}\end{array}$ & $\begin{array}{l}\text { Sensitivity } \\
\left(\mathrm{ng} \mathrm{ml}^{-1}\right)^{\mathrm{b}}\end{array}$ & $\begin{array}{l}\text { Intra-assay } \\
\text { precision }^{c}\end{array}$ & $\begin{array}{l}\text { Interassay } \\
\text { precision }^{\mathrm{d}}\end{array}$ & $\begin{array}{c}\text { Accuracy } \\
(\% \text { recovery })^{e}\end{array}$ \\
\hline Progesterone (extracted plasma) & $78 \pm 4(10)$ & $0.19(10)$ & $6.6(10)$ & $11.1,8.6(10)$ & $114 \pm 5(7)$ \\
\hline Oestrone (hydrolysed/extracted plasma/urine) & $89(2)$ & $0.05(2)$ & $7.2(10)$ & $12.9,11.6(4)^{f}$ & $110 \pm 8(7)$ \\
\hline Oestradiol (extracted plasma) & & $0.003(4)$ & $4.8(10)$ & $13.2,9.6(4)$ & $103 \pm 6(14)$ \\
\hline Oestradiol (hydrolysed urine) & $92(2)$ & $0.003(2)$ & $3.3(10)$ & $16.3,19.6(6)^{f}$ & $105 \pm 11(7)$ \\
\hline Oestrone-3-conjugates (plasma) & - & $0.08(13)$ & $5.4(10)$ & ND & \\
\hline Oestrone-3-conjugates (urine) & - & $0.08(13)$ & $6.7(10)$ & $13.1,9.0(10)$ & $97 \pm 6(7)$ \\
\hline Pregnanediol-3 $3 \alpha$-glucuronide (urine) & - & $0.42(8)$ & $4.1(10)$ & $5.6,13.4(7)$ & $99 \pm 11(7)$ \\
\hline LH (plasma) & - & $2.0^{\mathrm{B}}$ & $13.1(11)$ & $11.3(11)$ & $87 \pm 4(8)$ \\
\hline
\end{tabular}

¿Values are means \pm SEM (number of extractions, each of 20-30 samples).

${ }^{b}$ Calculated at $\% B: B_{0}=90$ (number of assays).

'Expressed as coefficient of variation, (number of replicates).

'Expressed as coefficient of variation, (number of assays); ND: not determined.

'Values are means \pm SEM (number of replicates).

'Replicates of urine subjected to sequential hydrolysis before assay and precision based on sum of the different fractions.

${ }^{8} \mathrm{mIU} \mathrm{ml}^{-1}$.

performed to determine whether regular handling, cloprostenol treatment and blood sampling, as carried out in Expts 1 and 2, influenced steroid excretion across the ovarian cycle.

\section{Hydrolysis and separation of conjugated oestrogens}

The most abundant conjugated oestrogens (unconjugated oestrone, oestrone glucuronide, oestrone sulfate, 'residual' oestrone, unconjugated oestradiol, oestradiol glucuronide, oestradiol sulfate, or 'residual' oestradiol) in matched blood $(n=12)$ and urine $(n=12)$ samples collected during inferred follicular and luteal phases in Expt 1 were determined. Each sample was subjected to sequential enzyme hydrolysis and ethyl acetate solvolysis, followed by determination of the concentration of liberated oestrone and oestradiol. Glass tubes, $20 \mathrm{ml}$, were used to extract four aliquots of each sample (plasma: $20 \mu \mathrm{l}$, urine $2 \mu \mathrm{l}$, made up to $50 \mu \mathrm{l}$ with Pas-Gel buffer $-0.04 \% \mathrm{NaH}_{2} \mathrm{PO}_{4}, 0.13 \% \mathrm{Na}_{2} \mathrm{HPO}_{4} \cdot 2 \mathrm{H}_{2} \mathrm{O}, 0.8 \% \mathrm{NaCl}$, $0.1 \% \mathrm{NaN}_{3}, 0.1 \%$ gelatine) with diethyl ether to remove any unconjugated oestrone and oestradiol. The aqueous phase was then hydrolysed for $10 \mathrm{~h}$ at $37^{\circ} \mathrm{C}$ with 300 Fishman-U of purified $\beta$-glucuronidase (Fluka (Sigma) Chemie AG, Buchs) contained in $50 \mu \mathrm{l}$ Pas-Gel buffer $\left(0.1 \mathrm{~mol} \mathrm{l}^{-1}, \mathrm{pH} 7.0\right)$. After extraction of the oestrogens cleaved from glucuronide(s), the aqueous phase was hydrolysed for $20 \mathrm{~h}$ at $37^{\circ} \mathrm{C}$ with $20 \mu \mathrm{U}$ of sulfatase (Fluka (Sigma)), added in $200 \mu \mathrm{l}$ phosphate hydrolysis buffer $\left(0.25 \mathrm{~mol} \mathrm{l}^{-1}, \mathrm{pH} 5.0\right)$; the hydrolysate was extracted to remove the oestrogens cleaved from sulfate(s). The remaining aqueous phase was made up to $600 \mu \mathrm{l}$ by the addition of $300 \mu \mathrm{l}$ phosphate hydrolysis buffer; it was acidified using sulfuric acid $\left(50 \mu \mathrm{l}, 0.03 \mathrm{~mol} \mathrm{l}^{-1}\right)$, sodium chloride $\left(100 \mu \mathrm{l}, 6.0 \mathrm{~mol} \mathrm{l}^{-1}\right)$ was added, and the remaining oestrogen conjugates were solvolysed using ethyl acetate $(4.0 \mathrm{ml})$ for $20 \mathrm{~h}$ at $40^{\circ} \mathrm{C}$ (Hawkins and Oakey, 1974). The original conjugated form(s) of any oestrone and oestradiol liberated via solvolysis was not specifically identified, and is herewith referred to as 'residual' conjugates. Hydrolysis and solvolysis efficiencies were estimated by includ- ing known amounts of specific oestrone conjugates in each incubation and measuring the amount of oestrone liberated: with oestrone-3-glucuronide and oestrone-3-sulfate, respectively, glucuronidase hydrolysis was thus estimated as $84 \pm 4 \%$ efficient $(n=6)$ at cleaving glucuronides and as $4.8 \pm 0.2 \%$ efficient at cleaving sulfates; with oestrone-3-sulfate, sulfatase hydrolysis was estimated as $94 \pm 6 \%$ efficient $(n=6)$; solvolysis was estimated as $65 \pm 6 \%$ efficient $(n=6)$ with oestrone-3glucuronide, and $69 \pm 7 \%$ efficient $(n=6)$ using oestrone-3sulfate (Table 1 ).

After extraction, plasma and urinary oestrone and oestradiol were reconstituted in iso-octane $(1 \mathrm{ml})$ and subjected to celite column chromatography, performed according to the method of Abraham et al. (1970) and Anderson et al. (1976). Cochromatography separation- and recovery-efficiency were estimated by adding tritiated oestradiol (2000 c.p.m., sp. act. $51.3 \mathrm{Ci} \mathrm{mmol}{ }^{-1}$, Amersham International, Amersham) and tritiated oestrone ( 2000 c.p.m., sp. act. $90 \mathrm{Ci} \mathrm{m^{-1 }}$ ) to individual samples. Distinct elution peaks of radioactivity in the appropriate fractions for oestrone and oestradiol confirmed their chromatographic separation, while recovery of oestrone and oestradiol was estimated as $80-90 \%$. Chromatography buffer blanks gave immunoactive estimates below or at the sensitivity limit of the assay. After separation, the eluates were evaporated and the residues were reconstituted in oestrone assay buffer (two aliquots each in $0.5 \mathrm{ml}$ buffer) or oestradiol assay buffer (two aliquots each in $0.5 \mathrm{ml}$ buffer).

\section{Hormone assays}

Oestrogens in plasma and urine. After hydrolysis, extraction and chromatographic separation, the reconstituted oestrogens in plasma $(8 \mu \mathrm{l}$ in $200 \mu \mathrm{l}$ buffer) and urine $(0.08-0.8 \mu \mathrm{l}$ in $20-$ $200 \mu \mathrm{l}$ buffer) were assayed in duplicate. Sample unconjugated oestrogens were assayed in duplicate in plasma $(20 \mu \mathrm{l})$ and urine $(2 \mu \mathrm{l})$ after extraction and chromatography. Commercial radioimmunoassay kits for oestrone (bioMerieux, Marcy l'Etoile) and 

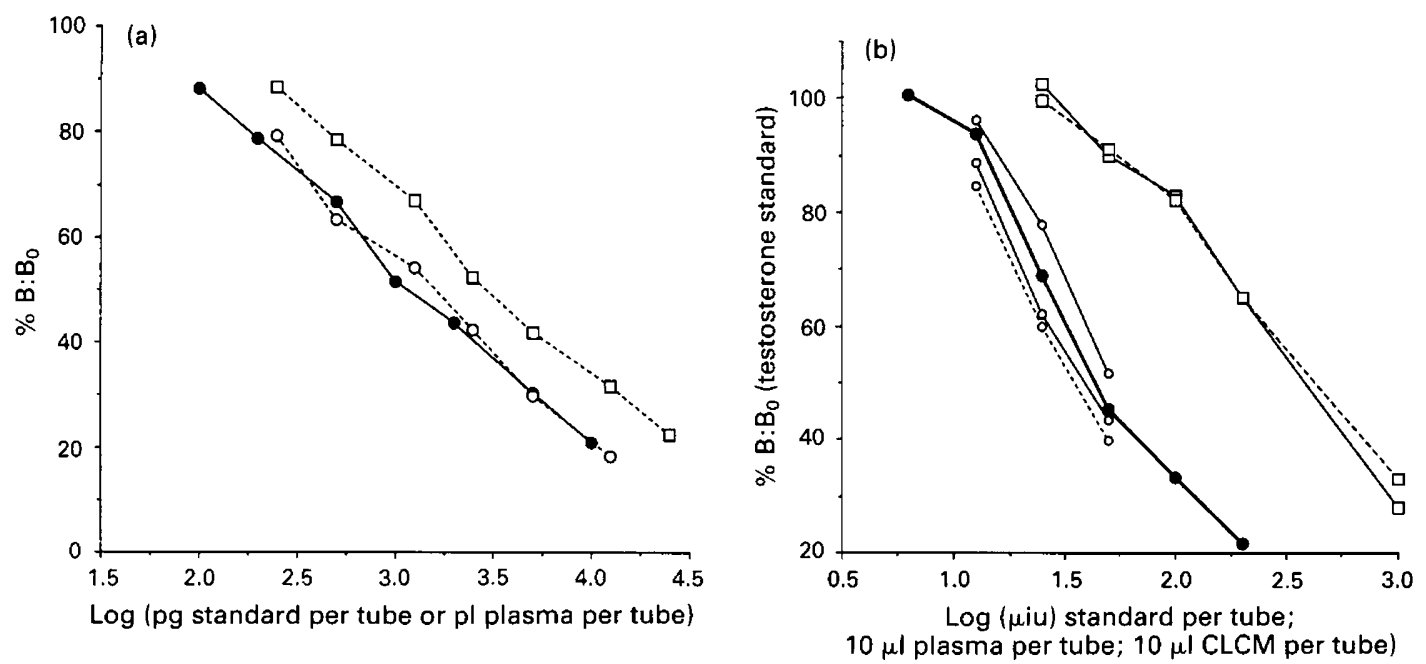

Fig. 1. Assay validation. (a) Displacement of [ $\left.{ }^{125} \mathrm{I}\right]$ progesterone from antiserum by serial dilutions of $(O)$ progesterone standard, and $(\square)$ pre-ovulatory and $(O)$ post-ovulatory plasma samples obtained from Goeldi's monkey. Dilutions of standard and sample giving equivalent displacement of binding were matched and subjected to two-way ANOVA for repeated measures. For assay validation, $F$ values for interactions between dilution and preparation with $P>0.05$ were interpreted as evidence of parallelism, for the progesterone radioimmunoassay and all other assays used in this study. (b) Displacement of testosterone standard by $(O)$ incubates of post-ovulatory Goeldi's monkey plasma and $(\bigcirc)$ human reference preparation from the LH bioassay; $(\square)$ effects of incubating Leydig cells with marmoset corpus luteum conditioned medium (CLCM) and serially diluting the incubates prior to inclusion in the testosterone radioimmunoassay.

oestradiol (Baxter, Merx \& Dade AG, Düdingen) were used for immunoactive determinations. Details of assay validation with the study species are given (Table 1, see also legend to Fig. 1).

Plasma and urinary oestrone-3-conjugates. Oestrone-3-conjugates were estimated directly in plasma and urine samples using a non-specific radioimmunoassay (Eastman et al., 1984). The antiserum was raised in a rabbit against oestrone- $\beta$-D-glucuronide sodium salt-BSA, and demonstrated a crossreactivity of 0.34 with oestrone, 0.26 with oestrone-3-sulfate, 0.02 with oestradiol-3-glucuronide, and 0.001 with oestradiol and oestradiol-3-sulfate. Oestrone- $\beta$-D-glucuronide sodium salt (E1752, Sigma) was used as standard, and $\left[6,7 \cdot{ }^{3} \mathrm{H}\right] 1,3,5(10)$ oestratrien-3-ol-17-one 3-glucuronide (sp. act. $53 \mathrm{Ci} \mathrm{mmol}^{-1}$, Steroid Biochemistry Group, University College, London) as tracer. Plasma samples $(10 \mu \mathrm{l})$ and urine samples $(0.2 \mu \mathrm{l})$ were assayed in duplicate. Details of assay validation are given (Table 1).

Plasma progesterone. Progesterone was extracted from plasma in duplicate, by shaking $20 \mu \mathrm{l}$ of plasma, made up to $100 \mu \mathrm{l}$ with Pas-Gel buffer, with 30 volumes of petroleum ether for $40 \mathrm{~min}$. The mean efficiency of each extraction was monitored by adding 1500 c.p.m. of $\left[{ }^{3} \mathrm{H}\right]$ progesterone to five separate tubes (Table 1). Progesterone was measured using the double-antibody iodinated radioimmunoassay described by Döbeli (1980); details of assay validation for this study are given (Table 1 and Fig. 1a).

Urinary pregnanediol-3a-glucuronide. Pregnanediol-3a-glucuronide was estimated in urine samples $(2.5 \mu \mathrm{l}$ undiluted sample, in duplicate) using a specific radioimmunoassay, as described by Jurke et al. (in press). Details of assay validation are given (Table 1).

Bioactive plasma $\mathrm{LH}$. Bioactive plasma $\mathrm{LH}$ was measured using the mouse Leydig cell in vitro bioassay of van Damme et al. (1974) with modifications as described by Hearn et al. (1988). Plasma samples were assayed in duplicate at two dilutions (2.5 and $5.0 \mu \mathrm{l}$ equivalents). Testosterone production by Leydig cells was measured by radioimmunoassay as described by Hodges et al. (1987). This bioassay has been validated for use with marmoset plasma (Harlow et al., 1984; Hearn et al., 1988). Further validation to determine whether the increase in bioactive $\mathrm{LH}$ concentrations during the luteal phase of the marmoset ovarian cycle, as reported by Harlow et al. (1984) and Abbott et al. (1988), was physiologically meaningful or an artefact of the LH bioassay is reported here. Serial dilutions of media conditioned with marmoset corpus luteum or culture medium alone were tested for their effects in the LH bioassay and testosterone radioimmunoassay. Incubation of Leydig cells with culture medium alone had no effect on testosterone production. In contrast, incubation of cells with media conditioned with corpus luteum generated incubates that gave dose-dependent displacement curves in the testosterone radioimmunoassay (Fig. Ib). Addition of the same corpus luteum conditioned media to the testosterone radioimmunoassay failed to cause displacement of iodinated testosterone from antibody directly, showing that medium conditioned with corpus luteum did not contain steroids that crossreacted with anti-testosterone. These findings support the view that media conditioned with corpus luteum, where corpora lutea were obtained from the common marmoset, contains factor(s) that stimulate the production of testosterone by mouse Leydig cells. This validation step carried out with the common marmoset was performed simultaneously with, Downloaded from Bioscientifica.com at 04/26/2023 12:39:07PM 
and is relevant to, the validation of this bioassay for measuring bioactive LH in Goeldi's monkey; details of this validation are presented (Table 1 and Fig. 1b). Goeldi's monkey urine gave displacement curves of slope significantly different from that obtained with the human reference preparation $(P<0.05)$; urinary $\mathrm{LH}$ was therefore not measured in this study.

\section{Creatinine determination}

Creatinine was measured in each urine sample to control for variation in liquid intake and its effects on urinary metabolite concentration, within and between study animals, and concentrations of urinary hormones were expressed as mass $\mathrm{mg}^{-1}$ creatinine. A Beckman Creatinine Analysor 2 (Beckman Instruments, Inc, Fullerton, $\mathrm{CA}$ ) was used. All samples were diluted 1:20 before creatinine determination and interassay precision was $2.9 \%(n=10)$.

\section{Statistical analysis}

Data points obtained between day -8 and day 6 of each cycle were log-transformed and categorized according to whether they were collected at day -8 to -6 , day -5 to -3 , day -2 to 0 , day 1 to 2 , day 3 to 4 , and day 5 to 6 , to determine the time relative to ovulation when the first significant $(P<0.05)$ increase in each hormone occurred. This produced a data matrix containing no empty cells and normally distributed values, which was then analysed by a blocked design one-way ANOVA with cycle-number as a repeated measure. Post hoc comparisons between pairs of time intervals were performed using the T-Method (Sokal and Rohlf, 1981).

\section{Results}

\section{Experiment 1}

Each of the three females demonstrated a repeating biphasic cycle for plasma progesterone and the absolute concentrations in each phase reflected those determined by Harlow et al. (1983) for the common marmoset. Harlow et al. performed laparotomy and demonstrated that progesterone first exceeds $10 \mathrm{ng} \mathrm{ml}^{-1}$ plasma 1 day after ovulation has occurred (day 0 ). The follicular phase was defined as that period during which progesterone concentration remains below $10 \mathrm{ng} \mathrm{ml}^{-1}$, and the luteal phase as the remaining period of the cycle during which concentrations remain between 10 and $150 \mathrm{ng} \mathrm{ml}^{-1}$ plasma (Harlow et al., 1983). On the basis of the inter-specific similarity with regard to progesterone profiles, but in the absence of confirmation of ovulation per se, in this study of Goeldi's monkey the day of ovulation (day 0 ) is herewith also defined as that preceding the day on which progesterone concentrations first exceeded $10 \mathrm{ng} \mathrm{ml}^{-1}$ (day 1 of the luteal phase). We used this definition to normalize the data obtained for plasma progesterone across three to four apparent ovarian cycles from each of the three study females. The average plasma progesterone profile obtained using this method is presented (Fig. 2a) and estimates for the duration of inferred follicular and luteal phases and entire ovarian cycles, based on individual plasma progesterone profiles, are shown (Table 2). The mean average durations
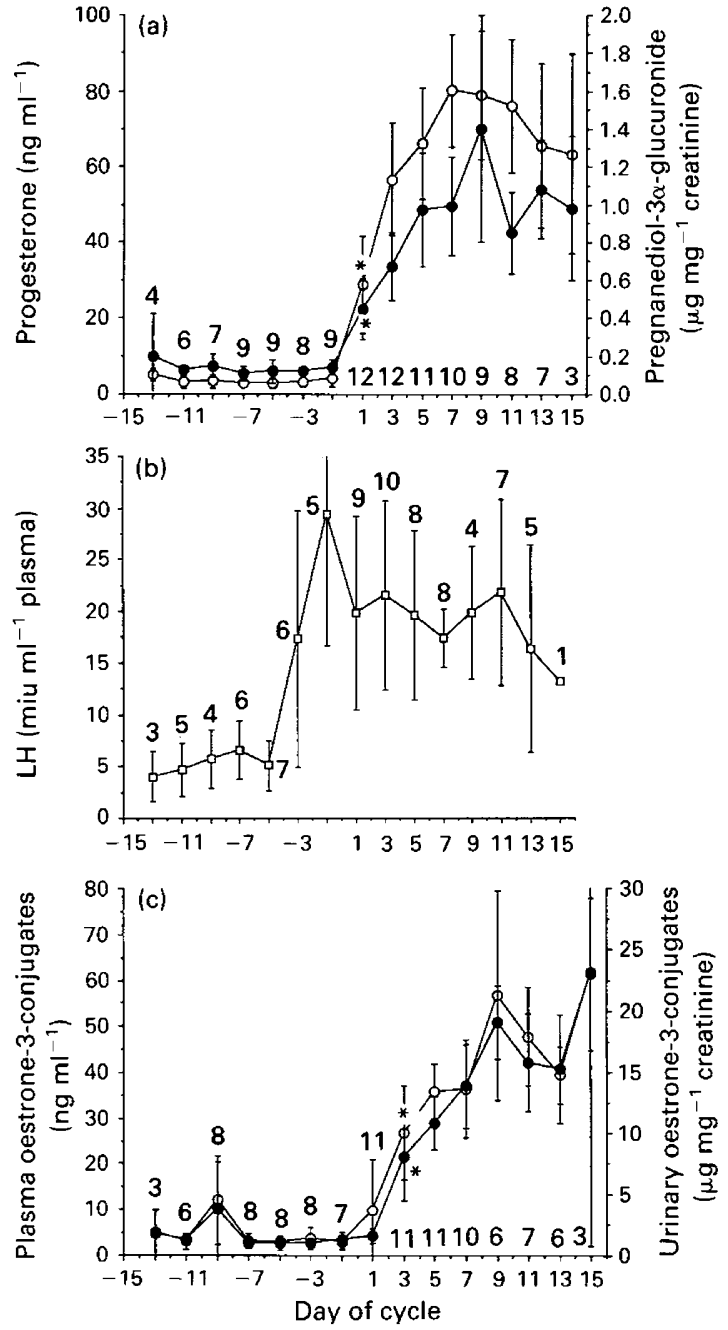

Fig. 2. Concentrations (mean $\pm 95 \%$ confidence limits) of (a) plasma (O) progesterone and urinary (O) pregnanediol-3 $\alpha$-glucuronide, (b) plasma bioactive $\mathrm{LH}$, and (c) plasma $(\mathrm{O})$ and urinary $(-$ ) oestrone-3conjugates. Values are expressed as the antilog of the mean of transformed data. The number at each two-day interval refers to the number of cycles for which matched samples were obtained at that stage of the cycle. Differences in sample sizes between (a), (b) and (c) are due to insufficient plasma for some determinations. ${ }^{*}$ The first significant increase in plasma or urinary concentration.

Table 2. Duration of ovarian cycles and their constituent phases based on concentration of progesterone in plasma of Goeldi's monkey

\begin{tabular}{lcll}
\hline Female & $\begin{array}{c}\text { Ovarian cycle } \\
\text { (days) }\end{array}$ & $\begin{array}{c}\text { Follicular phase } \\
\text { (days) }\end{array}$ & $\begin{array}{c}\text { Luteal phase } \\
\text { (days) }\end{array}$ \\
\hline 1 & $25,23,24$ & $12,10,9,12$ & $13,13,15,13$ \\
2 & $23,26,23$ & $10,11,9,12$ & $13,15,14$ \\
3 & $22,25,23$ & $10,11,10,12$ & $12,14,13,14$ \\
\hline
\end{tabular}

Duration of ovarian cycle calculated as the sum of a follicular phase and the succeeding luteal phase. 
Table 3. Relative abundance of unconjugated and conjugated oestrogen fractions in the plasma and urine of cyclic female Goeldi's monkey

\begin{tabular}{|c|c|c|c|c|c|c|c|c|}
\hline \multirow[b]{2}{*}{ Source } & \multicolumn{4}{|c|}{ Oestrone } & \multicolumn{4}{|c|}{ Oestradiol } \\
\hline & Unconjugated & Glucuronide & Sulfate & Residual & Unconjugated & Glucuronide & Sulfate & Residual \\
\hline \multicolumn{9}{|l|}{ Plasma (nmol l-1) } \\
\hline Follicular phase & $0.0-0.4$ & $4.7-15.2$ & $1.7-2.6$ & 0.0 & $0.4-1.1$ & $0.3-0.4$ & $0.1-0.6$ & 0.0 \\
\hline Luteal phase & $0.4-1.5$ & $19.1-103.0$ & $36.4-114.5$ & 0.0 & 0.4 & $1.2-3.5$ & $1.7-3.5$ & 0.0 \\
\hline \multicolumn{9}{|c|}{$\begin{array}{l}\text { Urine } \\
\text { (nmol mg } \\
-1 \\
\text { creatinine) }\end{array}$} \\
\hline Follicular phase & 0.0 & $3.4-5.4$ & 0.4 & 0.0 & 0.0 & $<0.4$ & $<0.4$ & 0.0 \\
\hline Luteal phase & $0.9-1.2$ & $23.0-55.7$ & $2.3-6.3$ & 0.4 & 0.0 & $0.9-1.4$ & 0.4 & 0.0 \\
\hline
\end{tabular}

Values given represent the range obtained when two mid-phase matching plasma and urine samples were measured in each of three females (i.e. six samples per range).
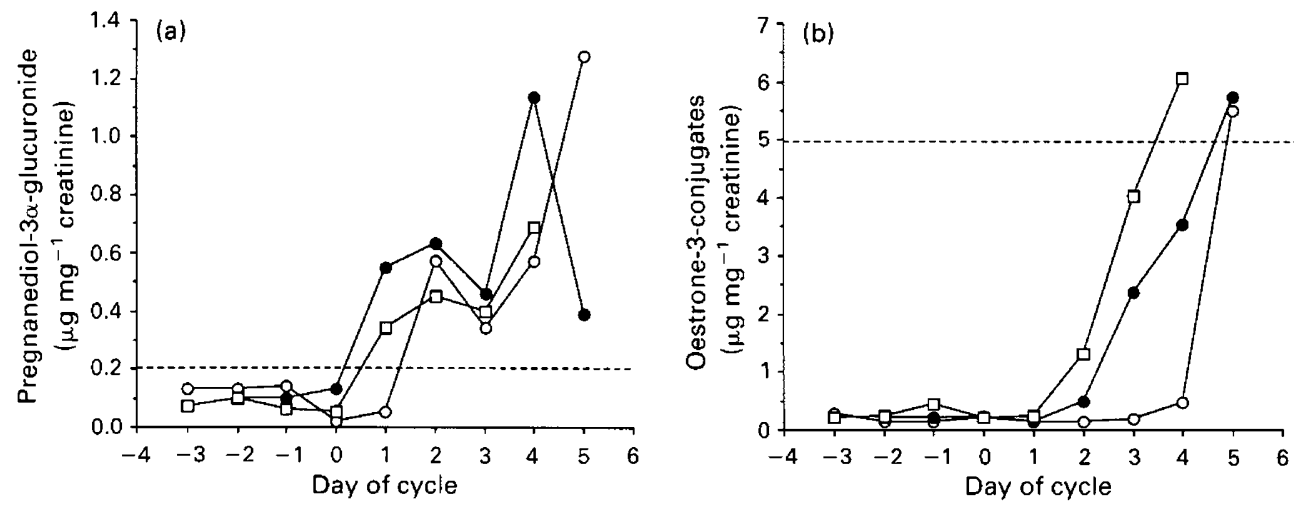

Fig. 3. Daily changes across the inferred peri-ovulatory period in the urinary concentration of (a) pregnanediol-3 $\alpha$-glucuronide and (b) oestrone-3-conjugates in three females from which matched blood and urine samples were obtained each day. Each dashed line indicates the proposed, metabolite-specific threshold value for the onset of the luteal phase. The same symbols were used for each female in (a) and (b).

( \pm SEM) for ovarian cycle, follicular phase and luteal phase, on the basis of cyclical plasma progesterone titres with a sampling frequency of three times per week, were $23.9 \pm 0.4$ days, $10.7 \pm 0.3$ days and $13.5 \pm 0.3$ days, respectively. Bioactive LH rose between day -5 and day -1 of the inferred follicular phase and remained high until day 13 of the inferred luteal phase $(F(5,7)=3.79, P=0.06$ ) (Fig. $2 b$ ).

The concentrations of urinary pregnanediol-3 $\alpha$-glucuronide (Fig. 2a) and plasma progesterone demonstrated a high, positive correlation across the sampling period $(r=0.80$, d.f. $=158$, $P<0.0001$ ). During the follicular phase, the average urinary concentrations of pregnanediol- $3 \alpha$-glucuronide remained below $0.20 \mu \mathrm{g} \mathrm{mg}^{-1}$ creatinine. Only six (i.e. $12.0 \%$ ) of the 50 samples analysed during inferred follicular phases exceeded this concentration; all such samples were followed by an immediate return to below $0.20 \mu \mathrm{g} \mathrm{mg}^{-1}$ creatinine in the next sample. In addition, four of these exceptions were determined in urine samples collected 1-2 days after the end of the preceding luteal phase, suggesting a short lag phase between progesterone synthesis and excretion in some ovarian cycles. At days $1-2$ after the inferred day of ovulation, the increase in plasma progesterone was reflected by a significant increase in pregnanediol- $3 \alpha$ - glucuronide concentrations $(F(5,9)=23.3, P<0.001)$ (Fig. 2a). At days 3-4 after ovulation, all concentrations of urinary pregnanediol-3 $\alpha$-glucuronide were greater than $0.40 \mu \mathrm{g} \mathrm{mg}^{-1}$ creatinine, and urinary pregnanediol-3 $\alpha$-glucuronide averaged approximately $1.0 \mu \mathrm{g} \mathrm{mg}^{-1}$ creatinine in urine collected during the remainder of the luteal phase in each of these nonconception cycles. Only two of 68 urine samples (i.e. $2.9 \%$ ) contained less than $0.20 \mu \mathrm{g}$ pregnanediol-3 $\alpha$-glucuronide $\mathrm{mg}^{-1}$ creatinine during the luteal phase; both of these samples were collected on the first day on which the concentration of plasma progesterone exceeded $10 \mathrm{ng} \mathrm{ml}^{-1}$, suggesting that there is a $I$ day lag phase between progesterone synthesis and excretion in a small proportion of ovarian cycles.

Oestrone glucuronide was the major plasma oestrogen measured during the follicular phase, whereas oestrone glucuronide and oestrone sulfate each accounted for approximately $50 \%$ of the plasma oestrogen measured during the luteal phase (Table 3). Approximately 10-15 times more oestrogen (i.e. oestrone and oestradiol) was present in the circulation during the luteal phase than in the follicular phase. In urine, more than $90 \%$ of the oestrogen measured in both the follicular and luteal phases was in the form of oestrone glucuronide. The profiles 
obtained for oestrone-3-conjugates in plasma and urine from the direct radioimmunoassay are presented (Fig. 2c). Mean concentrations of oestrone-3-conjugates were low during the inferred follicular phase, except on days -9 to -8 ; these average values included some samples collected at the onset of a 9-10 day follicular phase, and suggest a lag phase in oestrogen secretion and excretion at the end of the progesterone-defined luteal phase of some ovarian cycles. The first significant increase in plasma $(F(5,7)=19.8, P<0.001)$ and urinary $(F(5,9)=$ $33.5, P<0.001$ ) oestrone-3-conjugates occurred at days $3-4$.

\section{Experiment 2}

Cloprostenol doses of $10-20 \mu \mathrm{g} \mathrm{kg}^{-1}$ were necessary for a luteolytic effect to be observed; this represents 8-16 times the dose to which the marmoset is sensitive. In this experiment, we treated each of the three females with two injections of cloprostenol, each consisting of $6.5 \mu \mathrm{g}$ cloprostenol (taken as equivalent to $10 \mu \mathrm{g} \mathrm{kg}^{-1}$ ) and given $1-2 \mathrm{~h}$ apart; this treatment had no visible side effects. Plasma progesterone was measured and used to estimate the day of ovulation as described above; ovulation occurred on day 10,12 and 13 after cloprostenol injection. The individual profiles that were obtained for pregnanediol-3 $\alpha$-glucuronide and oestrone-3-conjugates in the matching urine samples are shown (Fig. 3). In the three females, urinary pregnanediol-3a-glucuronide (Fig. 3a) had increased to a 'luteal-phase' value in excess of $0.20 \mu \mathrm{g} \mathrm{mg}^{-1}$ creatinine by day 1 or 2 of the inferred luteal phase. In the case of urinary oestrone-3-conjugates, Carroll et al. (1990) defined a concentration of greater than $5.0 \mu \mathrm{g}$ urinary oestrone-3-conjugates $\mathrm{mg}^{-1}$ creatinine as being characteristic of the luteal phase. In the present experiment, however, the three females did not secrete more than $5.0 \mu \mathrm{g} \mathrm{mg}^{-1}$ creatinine until day 4 or 5 (Fig. $3 \mathrm{~b}$ ). Follicular values of urinary oestrone-3-conjugates were somewhat reduced in these females relative to those observed in Expt 1 (Fig. 3b versus Fig. 2c).

\section{Experiment 3}

The excretion profiles of pregnanediol- $3 \alpha$-glucuronide and oestrone-3-conjugates during the sampling period of two of the females from Expt 3 are presented (Fig. 4). For all inferred ovulations $(n=6)$, the post-ovulatory increase in the urinary concentration of pregnanediol-3 $\alpha$-glucuronide to a lutealphase' value occurred at least two days before an increase to a 'luteal-phase' value by oestrone-3-conjugates. In some cases, a decrease to a 'follicular-phase' concentration by pregnanediol$3 \alpha$-glucuronide occurred before such a decrease by oestrone-3conjugates. On the basis of the urinary excretion profiles of pregnanediol-3 $\alpha$-glucuronide for the three females in Expt 3, estimates of the duration of the ovarian cycle of 24,23 and 24 days were obtained (Fig. 4). Estimates of individual follicular phases ranged from 8 to 11 days, and of individual luteal phases from 14 to 17 days. The 17 -day luteal phase was obtained with a postpartum cycle of the mated female (Fig. $4 \mathrm{~b}$ ), and it is therefore possible that this was a conception cycle, but with unsuccessful implantation. In general, however, the duration estimates obtained compared favourably with those obtained on the basis of cyclical changes in circulating progesterone in Expt 1 (see Table 2).
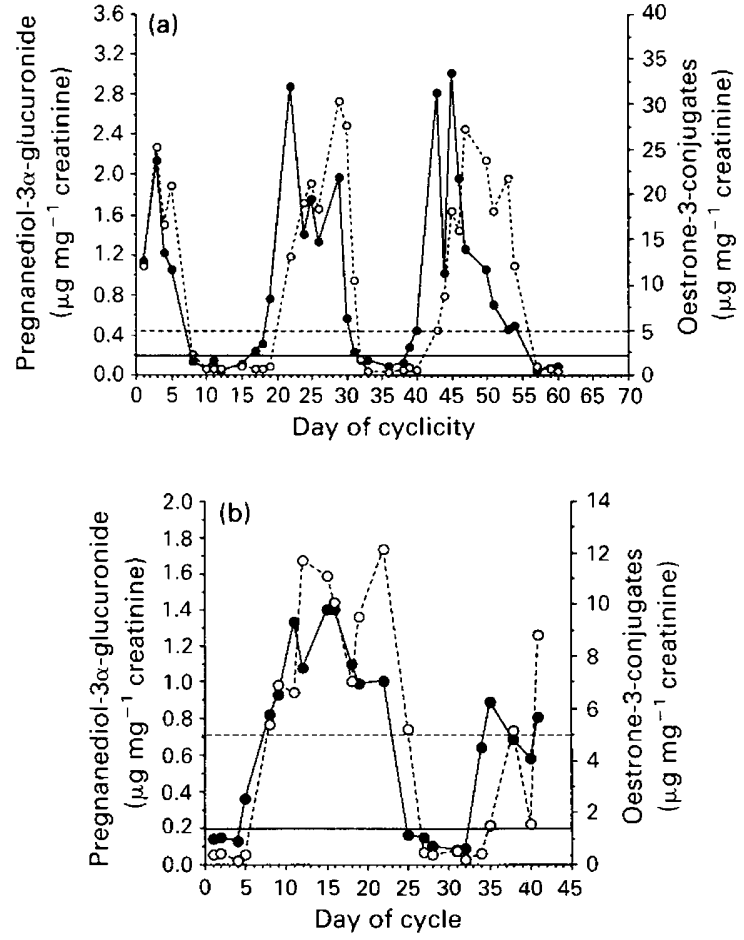

Fig. 4. Urinary concentrations of (-) pregnanediol-3 $\alpha$-glucuronide and $(O)$ oestrone-3-conjugates during individual ovarian cycles in two females (a) and (b). The solid line and dashed line represent the threshold values differentiating between the 'follicular phase' and 'luteal phase' for pregnanediol-3 $\alpha$-glucuronide and oestrone-3conjugates, respectively. In (b), the inferred luteal phase between day 5 and 22 was that of the postpartum ovarian cycle.

\section{Discussion}

The present study of Goeldi's monkey represents the first description of the non-conception ovarian cycle based on plasma reproductive hormones in this species. In this endangered primate, there is now (i) a description of cyclical changes in concentrations of progesterone, $\mathrm{LH}$ and oestrone-3conjugates in blood; (ii) a direct description of the temporal relationship between concentration changes in plasma progesterone and in a urinary progestagen metabolite, pregnanediol$3 \alpha$-glucuronide, and of the temporal relationship between concentration changes in plasma and urinary oestrone-3conjugates, and (iii) with immunoactive determination of urinary pregnanediol-3 $\alpha$-glucuronide, a validated, non-invasive method with which to retrospectively time the occurrence of ovulation to within an accuracy of 1 day. That a single absolute value of a urinary steroid metabolite can be used to differentiate follicular from luteal phases in all members of one captive population of a primate species, is, to our knowledge, an original finding. In Expts $1-3$, the value of $0.20 \mu \mathrm{g}$ pregnanediol-3 $\alpha$ glucuronide $\mathrm{mg}^{-1}$ creatinine served to distinguish between the progesterone-defined follicular phase $\left(<0.20 \mu \mathrm{g} \mathrm{mg}^{-1}\right.$ creatinine $)$ and the progesterone-defined luteal phase $(>0.20$ $\mu \mathrm{g} \mathrm{m}^{-1}$ creatinine) of, in total, 18 ovarian cycles in nine different females.

Supporting evidence for the timing of ovulation as estimated from plasma progesterone was obtained from the finding that 
mean LH bioactivity was maximal at the expected time, 1-2 days before inferred ovulation. The failure to detect a clear, significant surge in LH was compounded by two factors. First, the low sampling frequency (average once per 2.3 days) probably accounted for the high intercycle variation during the preovulatory period, because the peak daily LH value was probably missed in some cycles and second, LH bioactivity did not fall after ovulation as expected. A possible explanation for the latter observation is the presence of a 'non-LH endocrine factor(s)' that is secreted by the corpus luteum and which, when present in plasma samples, stimulates mouse Leydig cells to produce testosterone, thereby giving the impression of $\mathrm{LH}$ bioactivity. Evidence that marmoset corpus luteum produces such a factor is presented for the first time in this paper and our data for bioactive LH concentrations in Goeldi's monkey suggest that the same or a similar factor may also be produced by the corpus luteum of this species. Our inability to validate the $\mathrm{LH}$ bioassay (viz. parallelism) for routine use with urine samples from Goeldi's monkeys is not consistent with reports of Ziegler et al. (1989, 1990) and Carroll et al. (1990). This difference might, in part, be related to the fact that we did not stabilize the LH in frozen urine samples by the addition of glycerol, as recommended and done in the two studies of Ziegler and co-workers.

This study provides the first description for a New World monkey of the relative abundance of various conjugates of oestrone and oestradiol in the plasma during the ovarian cycle; the matched data obtained for urinary oestrogens confirm the findings of Carroll et al. (1990). Oestrone-3-glucuronide and oestrone-3-sulfate would appear to be the two most abundant forms of oestrone or oestradiol in the circulation in Goeldi's monkey, where they are present in approximately equivalent concentrations. In contrast, oestrone-3-glucuronide is apparently the major urinary metabolite of either urinary oestrone or urinary oestradiol. The shift from oestrone-3-sulfate to oestrone-3-glucuronide when comparing the relative abundance of these two conjugated oestrones in plasma versus urine might indicate a tendency to excrete oestrone-3-glucuronide more rapidly than oestrone-3-sulfate. If this is the case, retention of oestrone-3-sulfate might be related to some physiological function(s) performed by this conjugate, or a derivative of it. Such a possibility has also been suggested for the common marmoset (Harlow et al., 1984), in which oestrone-3-sulfate is also present in the circulation in high abundance. Unconjugated oestrogens in plasma accounted for only approximately $0.1 \%$ of the total oestrogen measured. This relatively low concentration does not preclude the usefulness of the unconjugated and, potentially, biologically-active oestrogens for monitoring ovarian cyclicity (e.g. Harlow et al., 1984).

Plasma concentrations of conjugated oestrone and oestradiol are high during the inferred luteal phase of the ovarian cycle and demonstrate only relatively low concentrations during the follicular phase, in Goeldi's monkey. Comparison of plasma oestrone-3-conjugates with the profile obtained for plasma progesterone would suggest that the circulating oestrogen measured in this study was also of ovarian origin. This same phenomenon has already been demonstrated for two other New World primates, namely, the owl monkey (Bonney et al., 1979), and the common marmoset (Hodges et al., 1983; Eastman et al., 1984). The profile of urinary excretion of oestrone-3- conjugates closely reflects that of oestrone-3-conjugates in the circulation, supporting the conclusions of previous studies based on urinary hormones only, that urinary oestrone-3conjugates are high during the luteal phase (Ziegler et al., 1989, 1990a; Carroll et al., 1990). Furthermore, studies based on the profiles of reproductive peptides and steroids in the urine of the cotton-top tamarin (Ziegler et al., 1987), golden-lion tamarin (French et al., 1992) and pygmy marmoset (Ziegler et al., 1990b), also strongly suggest that oestrogen excretion is high in the luteal phase relative to the follicular phase in clawed New World monkeys. Whereas Carroll et al. (1990) proposed a urinary concentration of $5.0 \mu \mathrm{g}$ oestrone-3-conjugates $\mathrm{mg}^{-1}$ creatinine as a threshold to indicate the first day of the luteal phase, we have now demonstrated a lag phase of 3-5 days between inferred ovulation and a significant increase in urinary oestrone-3-conjugates to 'luteal-phase' values. Using their definition of ovulation, Carroll et al. (1990) attempted to investigate the relationship between the 24 -day ovarian cycle and sexual behaviour. The present study would indicate a degree of inaccuracy of $2-4$ days $(8-17 \%$ of the cycle duration) in their estimate of the timing of ovulation, and this could explain why the few instances of mating that were observed did not occur during what was taken to be the peri-ovulatory period. It would appear to be important to include a matched analysis of blood hormones as part of the validation of those methods to increase the accuracy of non-invasive methods of reproductive monitoring.

Finally, to summarize the major findings of the present study of Goeldi's monkey, measurement of concentrations of reproductive steroids and peptides in blood has served to validate the non-invasive approach to monitoring ovarian function in this endangered New World primate. The monitoring of urinary pregnanediol-3 $\alpha$-glucuronide has been confirmed as a reliable indicator of progesterone-defined ovulation; in contrast, owing to an apparent post-ovulatory delay in oestrogen synthesis and excretion, this study has also established that urinary oestrone-3-conjugates represent a less reliable indicator of ovulation and, therefore, of reproductive condition.

This study was funded by a Project Grant from the Swiss National Research Foundation to R. D. Martin. Blood sampling was performed under an experimental licence issued in accordance with the Swiss Animal Protection Act (1978). We are extremely grateful to the Jersey Wildlife Preservation Trust and the Brookfield Zoo (Chicago Zoological Society) for providing us with our study animals on long-term loan for the scientific study of the conservation biology of Goeldi's monkey. We would like to thank K. Etter and U. Gonsalez for their technical assistance, and K. Zerobin for his cooperation. Finally, we express our sincere gratitude to R. D. Martin for making this study possible.

\section{References}

Abbott DH, Hodges JK and George LM (1988) Social status controls LH secretion and ovulation in female marmoset monkeys (Callithrix jacchus) Joumal of Endocrinology 117 329-339

Abraham GE, Tulchinsky D and Korenman G (1970) Chromatographic purification of estradiol-17 $\beta$ for use in radio-ligand assay Biochemical Medicine 3 365-368

Anderson DC, Hopper BR, Lasley BL and Yen SSC (1976) A simple method for the assay of eight steroids in small volumes of plasma Steroids 28 179-196 
Beck BB, Anderson D, Ogden J, Rettberg B, Brejla C, Scola R and Warneke M (1982) Breeding the Goeldi's monkey Callimico goeldii at Brookfield Zoo, Chicago International Zoo Yearbook 22 106-114

Bonney RC, Dixson AF and Fleming D (1979) Cyclic changes in the circulating and urinary levels of ovarian steroids in the adult female owl monkey (Aotus trivirgatus) Journal of Reproduction and Fertility 56 271-280

Carroll JB (1982) Maintenance of Goeldi's monkey Callimico goeldii at Jersey Wildlife Preservation Trust International Zoo Yearbook 22 101-105

Carroll JB (1985) Pair-bonding in Goeldi's monkey Callimico goeldii (Thomas, 1904) Dodo, Journal of the Jersey Wildife Preservation Trust 22 57-71

Carroll JB, Abbott DH, George LM and Martin RD (1989) Aspects of urinary oestrogen excretion during the ovarian cycle and pregnancy in Goeldi's monkey, Callimico goeldii Folia Primatologica 52 201-205

Carroll JB, Abbott DH, George LM, Hindle JE and Martin RD (1990) Urinary endocrine monitoring of the ovarian cycle and pregnancy in Goeldi's monkey (Callimico goeldii) Journal of Reproduction and Fertility 89 149-161

Christen A, Döbeli M, Kempken BN, Zachmann M and Martin RD (1989) Urinary excretion of oestradiol in the female cycle of Goeldi's monkey (Callimico goeldii) Folia Primatologica 52 191-200

Döbeli M (1980) Comparative studies in radioimmunoassay of progesterone in plasma and milk of cows using double antibody technique and dextran-coated charcoal separation. In Proceedings of the 2nd International Symposium of Veterinary Laboratory Diagnosticians Vol. 2 pp 207-215 Ed. HR Glättli, D König and F Paul Swiss Association of Veterinary Laboratory Diagnosticians, Lucerne

Eastman SAK, Makawiti DW, Collins WP and Hodges JK (1984) Patterns of excretion of urinary steroid metabolites during the ovarian cycle and pregnancy in the marmoset monkey Joumal of Endocrinology 102 19-26

French JA, deGraw WA, Hendricks SE, Wegner F and Bridson WE (1992) Urinary and plasma gonadotropin concentrations in golden lion tamarins (Leontopithecus $r$. rosalia) American Journal of Primatology 26 53-60

Harlow CR, Gems S, Hodges JK and Hearn JP (1983) The relationship between plasma progesterone and the timing of ovulation and early embryonic development in the marmoset monkey (Callithrix jacchus) Journal of Zoology 201 273-282

Harlow CR, Hearn JP and Hodges JK (1984) Ovulation in the marmoset monkey: endocrinology, prediction and detection Joumal of Endocrinology 103 17-24

Hawkins RA and Oakey RE (1974) Estimation of oestrone sulphate, oestradiol$17 \beta$ and oestrone in peripheral plasma: concentrations during the menstrual cycle and in men Joumal of Endocrinology 60 3-17

Hearn JP (1977) A device for restraining small monkeys Laboratory Animals 11 261-262
Hearn JP, Hodges JK and Gems S (1988) Early secretion of chorionic gonadotrophin by marmoset embryos in vivo and in vitro Journal of Endocrinology 119 249-255

Hodges JK, Brand HM, Henderson C and Kelley RW (1983) The levels of circulating and urinary oestrogens during pregnancy in the marmoset monkey (Callithrix jacchus) Journal of Reproduction and Fertility 67 73-82

Hodges JK, Cottingham PG, Summers PM and Yingnan L (1987) Controlled ovulation in the marmoset monkey (Callithrix jacchus) with human chorionic gonadotrophin following prostaglandin-induced luteal regression Fertility and Sterility 48 299-305

Jurke M, Pryce CR, Döbeli M and Martin RD Non-invasive detection and monitoring of pregnancy and the postpartum period in Goeldi's monkey (Callimico goeldii) using pregnanediol-3a-glucuronide American Joumal of Primatology (in press)

Pryce CR and Döbeli M (1992) Monitoring oestrogen excretion in Neotropical monkeys: coping with different metabolic strategies. In Proceedings of the First International Symposium on Faecal Steroid Monitoring in Zoo Animals pp 35-46 Ed. RM Buiter, W Schaftenaar and SI Dieleman. Royal Rotterdam Zoological and Botanical Gardens, Rotterdam

Sokal RR and Rohlf FJ (1981) Biometry. The Principles and Practice of Statistics in Biological Research. WH Freeman, New York

Summers PM, Wennick CJ and Hodges JK (1985) Cloprostenol-induced luteolysis in the marmoset monkey (Callithrix jacchus) Journal of Reproduction and Fertility 73 133-138

van Damme MP, Robertson DM and Diczfalusy E (1974) An improved in vitro bioassay method for measuring luteinizing hormone (LH) activity using mouse Leydig cell preparations Acta Endocrinologica 77 655-671

Warneke M (1992) Intermational Studbook: Callimico goeldii. Chicago Zoological Society, Chicago

Wolfheim JC (1983) Primates of the World. Distribution, Abundance and Conservation. University of Washington Press, Seattle and London

Ziegler TE, Bridson WE, Snowdon CT and Eman S (1987) Urinary gonadotropin and estrogen excretion during the postpartum estrus, conception and preg. nancy in the cotton-top tamarin (Saguinus oedipus oedipus) American Journal of Primatology 12 127-140

Ziegler TE, Snowdon CT and Warneke M (1989) Postpartum ovulation and conception in Goeldi's monkey, Callimico goeldii Folia Primatologica 52 206-210

Ziegler TE, Snowdon CT, Warneke M and Bridson WE (1990a) Urinary excretion of oestrone conjugates and gonadotrophins during pregnancy in the Goeldi's monkey (Callimico goeldii) Joumal of Reproduction and Fertility 89 163-168

Ziegler TE, Snowdon CT and Bridson WE (1990b) Reproductive performance and excretion of urinary estrogens and gonadotropins in the female pygmy marmoset (Cebuella pygmaea) American Joumal of Primatology 22 191-203 